\title{
Food contaminants
}

\author{
G. KAZANTZIS \\ Ph.D., F.R.C.S., M.R.C.P., M.F.C.M. \\ Department of Community Medicine, The Middlesex Hospital \\ Medical School, London
}

\begin{abstract}
Summary
With the increasing use of a large variety of chemicals, opportunities for contamination of food are becoming greater. Food may be involved following some accidental occurrence or from more general environmental contamination. Three examples are given: an outbreak of paralysis in Morocco involved 10,000 people who had ingested food adulterated with triorthocresyl phosphate; an epidemic of jaundice in London followed the contamination of flour with an epoxy resin hardener; organic mercury poisoning in an Arab country involved more than 6000 people who had eaten bread made from grain treated with a methyl mercury fungicide. The hazard which may arise from heavy metal accumulation in the body is discussed.
\end{abstract}

\section{Introduction}

The word 'contaminant' implies something that is not an intrinsic component or purposely added to food but one which is there either as a result of some accidental occurrence or because it is a more general environmental contaminant and so finds its way into water, crops or animal products consumed as food. In a sense the latter too is accidental contamination of a rather different kind and both will be considered here.

Fraudulent adulteration of food was common at one time in Britain when, for example, sweeteners in the form of lead salts used to be added to beverages the exposure of which, in a campaign launched by the Lancet, led to the first 'Food and Drugs Act' of 1860. The chemical manipulation of food in the effort to improve it has been dealt with in a previous paper and can also be associated with hazards.

\section{Accidental contamination}

In September 1959 an epidemic characterized by muscle cramps and paralysis broke out in the city of Mecknes, in Morocco, so that 700 people were admitted to hospital in the first week of the epidemic alone. The festivities occasioned by the birthday of the prophet were cancelled owing to this mysterious new illness thought at first to be a viral infection.

Following epidemiological investigation, which in- cluded a house-to-house survey, the viral theory for the origin of the disease was discarded in favour of some kind of food poisoning. The disease had spread in a disjointed fashion, only one section of the population, i.e. Moslems, had been affected and no infants were affected, even in families with multiple cases. Had an infective agent been responsible, spread through contact in crowded areas such as markets would have been more likely and, furthermore, all biological investigations had proved negative.

One child who developed the disease in hospital had eaten fritters brought in by relatives and, following such observations, it was soon realized that areas frequented by fritter vendors were much more heavily affected than others. The viral theory was finally abandoned when cooking oil available in Mecknes was found to contain a quantity of mineral oil, later identified as triorthocresyl phosphate (TOCP). TOCP, a known nerve poison, had previously been responsible for peripheral neuropathy in industrial workers in Britain.

In all, more than 10,000 people were affected throughout the country by paralysis before the end of the year, and 2 years later $15 \%$ of these still required medical care for various degrees of disability. This national catastrophe was brought about by adulteration of cooking with mineral oil which had been bought as surplus stock from an American Air Force base by an enterprising dealer (Albertini, Gross and Zinn, 1968).

Kopelman, Robertson and Sanders (1966) reported an epidemic of jaundice with unusual clinical features which involved eighty-four people living in the Epping district of Essex. Most of the cases occurred in members of families living together and there was a curious predilection for the professional classes. An infectious origin was sought, in particular viral hepatitis, glandular fever, brucellosis, Coxsackie virus infection, fascioliasis and leptospirosis, but all investigations proved negative. Eventually careful questioning revealed that the victims had eaten wholemeal bread produced by one Epping bakery, a coarse brown bread disliked by children. Some of this bread recovered from patients' homes 
subsequently produced liver damage in laboratory mice. As enquiries showed that other areas where flour from the same batch had been delivered had not experienced the disease, it was concluded that flour from the Epping baker had in some way become contaminated in transit. Indeed, a new bag of wholemeal flour had been opened and used a few days before the first case occurred. The flour had been conveyed by a van which also carried chemicals to a factory. Many chemicals had been carried, but on the day the flour had been delivered a spill had occurred in the van from a plastic jar holding 4-4' diamino diphenyl methane, an aromatic amine dissolved in butyrolactone which is used as a hardener for epoxy resin. A yellow substance was later extracted from the suspect bread which when given to mice produced liver damage. This substance, present in the wholemeal flour at the bottom of the sack in a concentration of 13 parts $/ 10^{6}$, was shown to be identical with the hardener. There had been no previous record of human poisoning with $4-4^{\prime}$ diamino diphenyl methane.

\section{Environmental contamination with heavy metals}

In the autumn of 1971 , a middle-eastern country purchased from international sources some 80,000 tons of mercury-dressed grain, both wheat and barley, for sowing as part of a large scale agricultural programme. The seed, which had been treated with a mercurial fungicide, was widely distributed through local farmers' unions. Unfortunately the consignment arrived late in the autumn so that many peasant farmers had already sown their summer harvest in the expectation that more seed was to come. Some of the dressed seed was ground into flour in village mills and made into bread, which was consumed by numerous households. Warnings on the sacks were written in English and Spanish, which of course were meaningless to an Arab population, although even strong government warnings on the handling of the seed were unfortunately ignored. Organo mercury poisoning was first diagnosed late in December, from 5 to 6 weeks after the eating of the contaminated bread had begun. During the next 3 months hospital admissions approached 300/day and there were also deaths in the villages. In all, over 6000 persons were hospitalized. The seed dressing involved was shown to be highly toxic methyl mercury, which damages the central nervous system with a selective affinity for the granular layer of the cerebellum and for the occipital cortex. A proportion of the survivors have been left with permanent neurological damage manifested by ataxia severe enough to prevent the victim walking or even feeding himself; constriction of the visual fields leading to blindness; deafness and dysphasia.
This condition has been known as Minamata disease ever since the discovery of methyl mercury poisoning, on a much smaller epidemic scale than the one here described, affecting the families of fishermen living in the vicinity of Minamata Bay in Japan in the 1950s. High concentrations of mercury were found in the brain and other organs of victims, also in fish and shellfish and in sludge taken from the bottom of the bay. Mercury was being discharged with the effluent of a chemical factory in which mercuric chloride was used as a catalyst in the manufacture of vinyl chloride. While the mercury had been discharged mostly in the less toxic inorganic form, it has since been shown that methyl mercury can be synthesized from inorganic mercury by bacteria capable of transferring a methyl group under the anaerobic conditions existing in the silt at the bottom of the bay. The methyl mercury was then concentrated in marine food chains until man and domestic animals eating fish from the bay were involved (Kazantzis, 1971).

In both Scandinavia and North America, the chlor-alkali and wood pulp industries have been responsible for the contamination of inland waterways with mercury. People with a high fish intake have been found to have raised blood and hair mercury levels, but no cases of poisoning from this source have been found. In Britain, a Working Party (1971) was set up to determine the amounts of mercury and certain other heavy metals in food and to report on these. Over 3000 samples of food were analysed and a total diet study was designed to estimate the average daily intake of mercury in the diet. Later, similar investigations were performed with regard to lead and cadmium. The mercury content of major foods in our diet was found to be low with an average intake of not more than $10 \mu \mathrm{g}$ /day. However, the mercury level in fresh fish and shellfish was higher than in other foods, in particular in fish from certain coastal areas, especially from the industrial estuaries of the Thames and Mersey, where concentrations of $0.5 \mathrm{mg} / \mathrm{kg}$ were found. However, few if any people in Britain subsist on locally caught fish so that the ingestion of consistently higher amounts of mercury from this source is unlikely.

Mercury, lead and cadmium are cumulative metals in the body and, in any consideration of the role of food as a vehicle for their absorption, the contribution from all other sources must also be taken into consideration. This is well illustrated by lead, which is present in trace amounts not only in food but in drinking water, especially soft, slightly acidic water, and which is also present in particulate form in the atmosphere from which it can be absorbed following inhalation. Increased lead absorption has been demonstrated in children living in the vicinity of lead smelting works, part of which may 
have been inhaled and the rest ingested following deposition in the domestic environment. With regard to lead, the U.K. Working Party (1972) again found no evidence of serious contamination of the national diet, their total diet studies showing an average daily intake in the region of $200 \mu \mathrm{g}$ with a further $20 \mu \mathrm{g}$ ingested from beverages. Lead levels in shellfish in industrial coastal areas were higher than average, as was the amount of lead in vegetables and other crops growing close to busy roads or in the vicinity of lead smelting works. The most striking finding of this survey was the considerably raised lead concentration for baby food sold in cans $(0.24 \mathrm{mg} / \mathrm{kg}$ compared with $0.04 \mathrm{mg} / \mathrm{kg}$ for the same food in jars) and urgent steps have been taken to remedy this source of lead intake in what may be a particularly vulnerable group.

A similar national food monitoring programme has been set up for cadmium, probably the most persistent of these three inessential metals in the body. There is evidence, again from Japan, that people living in an area where rice was grown in fields which had been irrigated with water contaminated by cadmium from a nearby zinc refinery developed a painful disease of the skeleton following a high cadmium intake over a period of time (Friberg, Piscator and Nordberg, 1971). The disorder, which the Japanese have called 'Ouch-Ouch Disease' is an osteomalacia which appears to be secondary to an acquired chronic renal tubular defect. A few cases of this disease have developed and have been investigated in Britain in industrial workers exposed over long periods to cadmium oxide fumes and dust.

Owing to the ubiquitous distribution of lead, mercury and cadmium in nature, small quantities are likely to have been present in man's food for a very long time. As far as we know they serve no useful purpose and can be regarded as inessential trace metals. The total body burden of these metals has, however, increased considerably in many populations since the advent of the technological age. A similar increase has also been found with other chemicals not considered here, notably the persistent fat soluble organo chlorine pesticides DDT, Aldrin and Dieldrin, traces of which have been found stored in body fat even in isolated island communities. Unwelcome intruders though these metals may be, the setting of too stringent criteria for levels in food would intensify the world's food problems in an unacceptable way. The important practical question which must be asked is, then, how much of these heavy metals can we tolerate in food without giving rise to ill effects?

Only a proportion of the metal intake is absorbed, although this proportion may vary widely. For example, particle size and shape and other physical and also chemical properties greatly affect absorption following inhalation, and the nature of the diet, such as calcium and protein content, influences absorption via the gastrointestinal tract. The chemical form is important, as can be shown by mercury where the elemental form is sparingly absorbed whilst the absorption of methyl mercury from the gut is almost complete. Selective organ deposition occurs, the target organ being that which first attains a critical level at which damage is evident. The critical organ accumulates metal when uptake exceeds elimination, and a steady state is reached when uptake and elimination are equal. The elimination rate can sometimes be expressed as a biological half-time which, with these contaminant metals, can be very long, for example, 70 days for methyl mercury whilst figures as long as 33 years have been quoted for cadmium.

Our knowledge is at present incomplete on the safe body burden of these metals, either in the current or in succeeding generations. However, while research on these fundamental aspects continues, it is necessary to set some limit on their intake as contaminants in food, compatible with what is believed at present to give rise to no ill effect. The process of evaluation which the joint Food and Agricultural Organization and World Health Organization Expert Committee on Food Additives (1972) has used for food additives for some years has followed the assumption that each day's intake is completely cleared by the body. Acceptance of a 'no effect' level in animal experiments has been followed by the application of an arbitrary safety factor and by the allocation of an Acceptable Daily Intake (ADI). This procedure has been found useful in dealing with the majority of the food additives. However, with the heavy metals an ADI would be inappropriate because of the cumulative nature and localization in susceptible organs of different forms of the metal with distinctive toxicological properties. Furthermore, a narrow margin exists between exposure in many populations and the level known to produce intoxication. An ADI based on animal studies, using a reasonable safety factor, might result in figures that would not permit an adequate food intake. Then again there is uncertainty concerning some of the essential facts on response to current levels of exposure. There is considerable individual variation in response; with the foetus, neonate and child being especially susceptible, the possibility of genetic effects exists, sub-clinical indices of effect require further delineation, and possible interactions between these metals and other chemicals present in food have yet to be investigated.

The cumulative nature of these metals and the daily variation in their intake makes it more appropriate to express intake for a longer time interval than one day. Current evaluation of a safe level for intake must remain subject to review as more data 
are collected and such contaminants in food cannot be regarded as acceptable in the way that deliberate food additives are. For these reasons the joint FAO/WHO Expert Committee allocated a Provisional Tolerable Weekly Intake rather than an Acceptable Daily Intake for lead, mercury and cadmium. The Provisional Tolerable Weekly Intake in adults for these three metals is shown in Table 1. These figures were arrived at by considering available data on metal levels in food, intake from other sources such as air and water; tissue levels associated with evidence of biochemical damage and, in a few instances, tissue levels corresponding with measured intakes.

TABLE 1. Evaluation of some food contaminants (FAO/WHO, 1972)

\begin{tabular}{|c|c|c|c|}
\hline \multirow{2}{*}{ Substance } & \multicolumn{2}{|c|}{$\begin{array}{l}\text { Provisional tolerable } \\
\text { weekly intake }\end{array}$} & \multirow{2}{*}{$\begin{array}{c}\text { Acceptable } \\
\text { daily } \\
\text { intake }\end{array}$} \\
\hline & $\mathrm{mg} /$ person & $\mathrm{mg} / \mathrm{kg}$ & \\
\hline \multicolumn{4}{|l|}{ Mercury } \\
\hline Total & $0 \cdot 3$ & 0.005 & None \\
\hline $\begin{array}{l}\text { Methyl mercury } \\
\text { (expressed as } \mathrm{Hg} \text { ) }\end{array}$ & $0 \cdot 2$ & 0.0033 & None \\
\hline Lead & 3 & 0.05 & None \\
\hline Cadmium & $0.4-0.5$ & $0.0067-0.0083$ & None \\
\hline
\end{tabular}

\section{Conclusion}

Much more work is required on the levels of contaminants in food based on internationally agreed methods of sampling and analysis; on food consumption patterns and dietary intake of heavy metals, and on the total body burden following measurement of intake from all sources. Such measures will enable governments to take scientifically based action to protect the average population from the hazards of these contaminants. In the meantime, environmental contamination should not be allowed to increase further. Waste disposal requires careful control by means of education and by enforcement of appropriate legislation. Certain sites will require repeated monitoring to ensure that control measures are adequate. Environmental surveys are necessary of metal content in the atmosphere, soil, water, vegetation and animal life, which latter, if chosen appropriately, may give valuable information on sources and levels of pollution. For example, observations on the growth of lichens and mosses, estimation of the metal content of vegetation growing on roadside verges, and of fish and shellfish in coastal waters can give a valuable indication of pollution levels.

Finally, recent experience shows that epidemics of chemical poisoning through the contamination of food or water may occur at any time and in any part of the world, whether industrialized or not. Such epidemics may pose as great a threat to the community as any outbreak of infectious disease. Since these epidemics, in their early stages and before their true nature is recognized, are liable to involve microbiologists, all concerned with the surveillance of infectious disease should be aware of the possibility so that the true source of the epidemic can be recognized and effective action taken as early as possible.

\section{References}

Albertini, A.V., Gross, D. \& Zinn, W.M. (1968) Triarylphosphate poisoning in Morocco, 1959. Georg Thieme Verlag: Stuttgart; Intercontinental Medical Book Corporation: New York.

Friberg, L., Piscator, M. \& Nordberg, G. (1971) Cadmium in the Environment. The Chemical Rubber Company: Cleveland.

KAZANTZIS, G. (1971) The poison chain for mercury in the environment. International Journal of Environmental Studies, 1, 301.

Kopelman, H., Robertson, M.H. \& SANders, P.G. (1966) The Epping jaundice. British Medical Journal, 1, 514.

SIXTEENTH REPORT OF THE JOINT FAO/WHO EXPERT COMMITTEE ON FoOd ADDITIVEs (1972) Evaluation of Certain Food Additives and the Contaminants Mercury, Lead and Cadmium. WHO: Geneva.

WORKINg PARTy ON THE MONITORING OF FoOdSTUfFs fOR Mercury and Other Heavy Metals, First Report (1971) Survey of Mercury in Food. H.M.S.O.: London.

Working PARTY ON THE MONITORING OF FoOdSTUfFs for Heavy Metals, Second RePoRt (1972) Survey of Lead in Food. H.M.S.O.: London. 